\title{
The Role of Leptin in Antipsychotic-Induced Weight Gain: Genetic and Non-Genetic Factors
}

\author{
Fabio Panariello, ${ }^{1}$ Gina Polsinelli, ${ }^{2}$ Carol Borlido, ${ }^{2}$ \\ Marcellino Monda, ${ }^{3}$ and Vincenzo De Luca ${ }^{2,4}$ \\ ${ }^{1}$ Spedali Civili Brescia, Department Mental Health, 25123 Brescia, Italy \\ ${ }^{2}$ Centre for Addiction and Mental Health, room 30, 250 College street, Toronto, ON, Canada M5T 1R8 \\ ${ }^{3}$ Dipartimento di Medicina Sperimentale, Seconda Università degli Studi di Napoli, 80131 Napoli, Italy \\ ${ }^{4}$ Department of Psychiatry, University of Toronto, Toronto, ON, Canada M5T $1 R 8$
}

Correspondence should be addressed to Vincenzo De Luca, vincenzo_deluca@camh.net

Received 2 January 2011; Revised 3 October 2011; Accepted 13 October 2011

Academic Editor: Angelo Pietrobelli

Copyright ( $) 2012$ Fabio Panariello et al. This is an open access article distributed under the Creative Commons Attribution License, which permits unrestricted use, distribution, and reproduction in any medium, provided the original work is properly cited.

\begin{abstract}
Schizophrenia is a chronic and disabling mental illness affecting millions of people worldwide. A greater proportion of people with schizophrenia tends to be overweight. Antipsychotic medications have been considered the primary risk factor for obesity in schizophrenia, although the mechanisms by which they increase weight and produce metabolic disturbances are unclear. Several lines of research indicate that leptin could be a good candidate involved in pathways linking antipsychotic treatment and weight gain. Leptin is a circulating hormone released by adipocytes in response to increased fat deposition to regulate body weight, acting through receptors in the hypothalamus. In this work, we reviewed preclinical, clinical, and genetic data in order to infer the potential role played by leptin in antipsychotic-induced weight gain considering two main hypotheses: (1) leptin is an epiphenomenon of weight gain; (2) leptin is a consequence of antipsychotic-induced "leptin-resistance status," causing weight gain.
\end{abstract}

\section{Background}

Schizophrenia has a worldwide prevalence of about one percent and has the potential for devastating emotional, physical, and mental consequences [1]. Antipsychotic drugs are the first line of treatment for those with schizophrenia and other psychoses [2]. There are two classes of antipsychotic medications used for treatment referred to as either typical or atypical. Typical antipsychotic drugs, like haloperidol, act as high-affinity antagonists for dopamine 2 (D2) receptors with a possibility of extrapyramidal side effects.

Second-generation antipsychotics (SGAs), like olanzapine and clozapine, have lower incidences of extrapyramidal side effects than typical antipsychotics because they are potent antagonists of serotonin $2 \mathrm{~A}\left(5-\mathrm{HT} 2_{\mathrm{A}}\right)$ rather than $\mathrm{D} 2$ receptor antagonists, with a higher affinity for the former. These drugs also inhibit the G-protein-coupled receptors for several other biogenic amines including cholinergic, adrenergic $(\alpha)$, histaminergic $(\mathrm{H})$, and dopaminergic receptors [3].
The increased use of atypical antipsychotics over the last decade has raised concerns about their metabolic side effects, such as weight gain, diabetes, and dyslipidemia [4]. In addition, medication-induced weight gain has been associated with a lower quality of life and noncompliance, which increases the risk for relapse. The higher risk of cardiovascular disease, leading to enhanced morbidity, mortality, significant economic cost, reduced quality of life, and lower compliance to treatment can be linked to the obesitogenic and diabetogenic capacity of these drugs [5].

However, the mechanisms of weight gain and dyslipidemia are poorly understood, and various parts of the endocrine system are presumably involved in these side effects. Several lines of evidence indicate that antipsychotic drugs elicit weight gain in some, but not all, individuals, suggesting a genetic predisposition [5]. Several hypotheses with regard to the biological mechanism underlying differential genetic liability have been suggested, mostly linked to genes which 
regulate appetite and food intake caused by SGA-induced stimulation of $5-\mathrm{HT} 1_{\mathrm{A}}$ and $5-\mathrm{HT} 6$ receptors, as well as $\alpha 2$ and muscarinic $\mathrm{M} 3$ receptors. Additionally, blocking receptors such as the $5-\mathrm{HT} 2_{\mathrm{C}}, 5-\mathrm{HT} 1_{\mathrm{B}}, \alpha 1, \mathrm{H} 1$ are known to result in additional weight gain [6-9].

Not surprisingly, hyperphagia is associated with weight gain in humans. Accordingly, it has been demonstrated that olanzapine-induced weight gain is caused by increased caloric intake, rather than alterations in basal energy expenditure [10]. It has been suggested that antipsychotics interact with the complex system of neurotransmitters, neuropeptides, and other modulators in brain neuronal circuits involving the hypothalamus and brain stem where a neuropeptidergic network mediates the actions of leptin and ghrelin to provoke disturbances in energy homeostasis, endocrine alterations, and body weight (BW) control [11].

Recent studies have shown that the hormones leptin and ghrelin are crucial elements of the hypothalamic neurocircuitry. Leptin, a $16 \mathrm{kD}$ peptide, is a cytokine-like molecule synthesized in white adipose tissue [12-14]. Leptin is a highly hydrophilic 167 amino acid protein and it is transported across the blood brain barrier by binding to the short form of the leptin receptor $[14,15]$ and is actively transported into the hypothalamus, where it acts to limit food intake. It is a product of the obese $(\mathrm{OB})$ gene located on chromosome 7 (7q31.3). Receptors for leptin are widely expressed throughout the central nervous system (CNS), but the major target of this hormone is the medial hypothalamus [16]. Although the leptin receptor is present as different splice-variant isoforms in the CNS, the form OBRb has the major role in its metabolic action $[12,16]$. The obese $\mathrm{db} / \mathrm{db}$ mouse and Zucker fa/fa rat represent naturally occurring "knockouts" of the leptin receptor, that have helped to validate the importance of CNS leptin action in energy homeostasis [17]. Exogenous leptin reduces appetite and feeding while leptin deficiency (both mice and humans with mutations in the leptin gene) causes extreme obesity and can lead to reproductive problems, bone formation deficiency, and cardiovascular complications [18-22]. It appears more involved in longterm regulation of energy, being released into the circulatory system as a function of energy stores.

In particular, leptin has multiple effects on energy homeostasis through activation of key hypothalamic nuclei and peptides to regulate energy balance. Leptin directly activates proopiomelanocortin (POMC) cells in the arcuate nucleus (ARC) to increase the release of melanocortin peptides including the POMC product $\alpha$-melanocyte-stimulating hormone $(\alpha-\mathrm{MSH})$. Melanocortin peptides inhibit food intake and regulates metabolism via energy storage, insulin secretion, and gastrointestinal motility predominantly through projections to MC4 receptor neurons [23-28].

Moreover, leptin also directly inhibits ARC, which produces agouti-related protein and neuropeptide Y. Hypothalamic ARC neurons - referred to as "first-order" neuronsreceive signals from the blood via the median eminence, and from the cerebrospinal fluid (CSF) via the third ventricle. The ARC contains two populations of neurons particularly relevant to feeding and satiety; the neuropeptide $\mathrm{Y}$
(NPY)/agoutirelated protein (AgRP) neurons and the proopiomelanocortin (POMC)/cocaine- and amphetamine-related transcript (CART) neurons $[25,26]$. These two groups of neurons interact with "second-order" neurons in other hypothalamic regions such as the paraventricular nucleus $(\mathrm{PVN})$, dorsomedial hypothalamus (DMH), ventromedial hypothalamus $(\mathrm{VMH})$, and lateral hypothalamic area (LHA).

Another key region implicated in research pertaining to weight and energy homeostasis is the caudate putamen $(\mathrm{CPu})$.

Dopamine (DA) neurons in the $\mathrm{CPu}$ have been shown to play a role in maintaining food intake and hunger levels [29-33]. Indeed, imaging studies have shown that severely obese individuals have decreased striatal D2 receptor (D2R) availability, and leptin-receptor-deficient obese rodents also show decreased D2R binding in striatum $[34,35]$. In contrast, chronic food restriction showed greater striatal D2R binding relative to ad libitum fed rats [35-37]. Genetic studies, although not always consistent, have reported that individuals carrying the Taq I A1 allele of the D2R gene, which was associated with decrease in $\mathrm{D} 2 \mathrm{R}$ in striatum by some investigators, are more vulnerable to addictive behaviors such as compulsive food intake and are more likely to be obese $[38,39]$. Leptin receptors are also present in the ventrotegmental area (VTA) and leptin targets dopaminergic and gammaaminobutyric acid neurons in this region critical to brain reward circuits, inducing phosphorylation of signal transducer and activator of transcription. Direct administration of leptin in the VTA causes decreased food intake $[40,41]$.

In humans, DA metabolite concentrations in the CSF decrease as leptin increases which could reflect inhibition of DA release by leptin. Indeed, preclinical studies have shown that short-term leptin treatment decreases both DA release and concentration in NAc (nucleus accumbens) and hypothalamus in a dose-dependent manner [41-43]. However, it is postulated that leptin may exert at least part of its influence through a pathway linked to H1-receptor, reducing food intake [44]. In fact leptin-induced food intake appears suppressed in H1 knockout mice $[45,46]$. This data suggests that hypothalamic histamine is a modulator of leptin activity. Hence, it is conceivable that antipsychotic drugs with a high affinity for H1-receptors could disarrange this pathway, inducing or exacerbateing a resistance to leptin action.

Beside the very rare case of genetic leptin deficiency, the vast majority of obese humans have high plasma leptin concentrations related to the size of adipose tissue. However, this elevated leptin signal does not induce expected responses (i.e., a reduction in food intake and an increase in energy expenditure), thus suggesting that most obese human subjects are resistant to the effects of endogenous leptin [47]. There is some evidence in regard of a "suppressor of cytokine signaling-3" (SOCS-3) that could act as an inhibitor of leptin signaling $[48,49]$. High leptin levels could determine an increase of SOC-3 that may in turn lead to resistance to leptin action [49].

Thus, leptin has been intensively investigated with respect to its association with changes in weight and glucose 
metabolism during treatment with various antipsychotics (APs). In that regard, our team reviewed longitudinal and cross-sectional studies which evaluated the effects of AP on leptin concentration, in addition to literature assessing genetic factors causing risk for fluctuations in leptin levels and risk for weight gain in response to AP treatment.

\section{Clozapine Treatment}

Clozapine has been a major focus of this research. Bromel et al. (1998) [50] evaluated serum leptin levels (SLLs) in 12 patients (9 schizophrenic and 3 schizoaffective disorder patients) in clozapine treatment. In this study, only 8 patients were additionally treated with conventional neuroleptics and other psychotropic drugs. The authors reported that after clozapine treatment, patients' SLLs differed significantly from levels measured afterward $(P<.0001)$, with concentrations at least doubling in 8 clozapine-treated psychotic patients, acutely evaluated (week 2) versus baseline, and no significant changes in more chronic treatment (up to the 10th week versus week 2). The net differences in BW and body mass index (BMI) between baseline at week 2 revealed positive correlations to the relative increases in the SLL. Kivircik et al. (2003) found that the analysis of variance on 19 clozapine-treated schizophrenic in- and outpatients who completed 10 weeks of treatment did not reveal any significant change in plasma leptin levels (PLLs), however, they reported that the patient gained 5\% of their BW, with a significant increase in BMI [51].

Theisen et al. (2005) investigated SLL and BMI in 12 clozapine treated patients with schizophrenia or schizoaffective disorders over a 10 -week drug assumption (8 patients were additionally treated with other AP, benzodiazepines, and/or antidepressant). The investigators observed that both SLL and BMI increased significantly from baseline [52].

Long-term treatment with clozapine and conventional APs has been studied in a longitudinal study by Hagg et al. (2001) [53]. They compared 41 schizophrenic patients in treatment with clozapine over approximatley 2.8 years with 62 taking conventional over the course of about 8.7 years. The authors reported an increase of PLL significantly associated with clozapine treatment in both men and women, but an increase in leptin levels with conventional AP treatment only in men.

Furthermore, Monteleone et al. (2002) found that a significant increase in circulating leptin may be a predictive factor for weight gain after clozapine treatment [54].

\section{Olanzapine Treatment}

Studies on olanzapine treatment have some mixed findings, but an increase in leptin levels has generally been observed. Graham et al. (2003) evaluated SLL levels at baseline, and again after 12 weeks, in nine first-episode psychosis patients. They did not observe any significant variation in SLL levels. However, they did find significant variation in BW [55]. On the other hand, Murashita et al. (2005) compared metabolic parameters before and after 6-month treatment with olanzapine in seven Japanese patients with schizophrenia. They found that the SLLs were significantly increased, but BW and BMI did not vary significantly after 6 months of treatment [56]. Hosojima et al. (2006) recruited 13 patients with schizophrenia in monotherapy with olanzapine for 4 weeks [57]. As seen in previous studies, SLL increased from baseline to week 4 . These changed in leptin levels appear to be quite rapid, and Wang et al. (2006) were the first to report these very early changes in leptin levels. They found a rapid increment in the PLLs at the fourth hour after the beginning of the olanzapine treatment in 9 schizophrenic patients. This increment stayed stable in week 2 [58].

Interestingly, Peña et al. (2008) observed a significant increment in SLL at week 8 but not in week 16 versus baseline in a sample of 60 olanzapine-treated patients after a switch from typical antipsychotics. They did, however, find a significant weight gain (WG) and BMI increase that paralleled leptin levels at week 8 [59]. Popovic et al. (2007) evaluated the modifications of SLL in 13 clozapine or risperidonetreated schizophrenic patients switched by conventional AP during 12 weeks [60]. A significant increase in SLL was observed at week 12. However, leptin concentrations in 18 patients treated with conventional AP were not different as compared with 20 healthy controls. In a longitudinal study, Eder et al. (2001) observed a concomitant significant increase in SLL over baseline and olanzapine-induced WG over baseline during an 8-week period in schizophrenic inpatients $(n=10)$, assigned to monotherapy with olanzapine and compared with healthy subjects [61]. Similarly, Atmaca et al. (2007) evaluated schizophrenic patients $(n=21)$, enrolled in olanzapine monotherapy during 6 weeks, and compared with healthy controls $(n=21)$ [62]. These investigators reported that leptin levels were increased from the baseline in the patients, while no difference was observed in the control group during the same period. In addition, the mean change in BW in the olanzapine group correlated with the change in leptin levels and in BMI [62].

The changes observed in leptin levels with regard to treatment with olanzapine have been seen as significantly varied in comparison to treatment with other APs. For example, a longitudinal study by Atmaca and collegues (2003), compared 45 patients with schizophrenia, treated by monotherapy with either quetiapine $(n=15)$, olanzapine $(n=$ $15)$, or haloperidol $(n=15)$ [63]. The patients were evaluated at baseline and after 6 weeks of medication. These authors found a marked increase in leptin levels for the olanzapine versus the quetiapine group and for the olanzapine versus the haloperidol group. In addition, Kraus and colleagues (1999) measured PLLs, weight, and BMI at baseline and weekly (over 4 weeks) in patients with schizophrenia who received clozapine $(n=11)$, olanzapine $(n=8)$, or treatment with haloperidol $(n=13)$, and in another group of patients receiving no pharmacological treatment $(n=12)$ [64]. They observed an early increase (at the end of the first week) of PLL associated with olanzapine and clozapineinduced WG. In contrast leptin levels, weight, and BMI remained stable in patients receiving haloperidol or no pharmacological treatment. 


\section{Treatment with Other Atypical and Typical Antipsychotics}

Zhang et al. (2003) evaluated the effects of risperidone and chlorpromazine on leptin, insulin secretion, and fat deposition, in 46 schizophrenic patients [65]. These authors have found a significant elevation in PLL after 10 weeks of medication, with significant interactions with gender. In their study, Herran et al. (2001) evaluated the effects on SLL of long-term typical and atypical antipsychotic treatment (at least 6 months) of 59 schizophrenic outpatients compared with 59 healthy controls [66]. Differences in leptin levels were significant in patients treated with atypical antipsychotics with gender effect (levels were higher in females). The authors have also noted that SLL in patients correlated significantly with WG and showed a trend for an association with BMI gains. Haupt and colleagues have pointed out no evidence of modulation of plasma leptin concentration by typical or atypical antipsychotics (olanzapine, risperidone) in 72 schizophrenic patients [67].

\section{Preclinical Research}

The findings in human studies are inconsistent with results from animal models and in vitro studies. In their experiments treating mature adipose cells from human mammary tissue with clozapine, Hauner et al. (2004) did not find any variations in insulin-stimulated glucose transport or leptin production [68]. Consistently, Cooper et al., (2008) using an animal model, performed a 20-day fixed-dosed treatment using 1, 2, or $4 \mathrm{mg} / \mathrm{kg} /$ day olanzapine in female rats, and did not find any significant differences across any of the cohorts in serum leptin levels at endpoint despite differences in weight gain [69]. On the other hand, Sondhi et al. (2006) found increases in serum leptin levels after 28 days of clozapine treatment in rats [70].

\section{Genetic and Pharmacogenetic Studies}

To our knowledge, rare mutations in leptin gene (LEP) and Leptin Receptor gene (LEPR) cause morbid obesity in studies using both human subjects or animal models. Several studies have shown modest effects of rs7799039 LEP (-2548 G/A functional polymorphism) and rs1137101 LEPR variants on BMI, and some research has associated the same polymorphisms with antipsychotic-induced weight gain, with some inconsistent results.

The first of these studies by Yang et al. (2007) examined the $-2548 \mathrm{G} / \mathrm{A}$ functional polymorphism in the leptin gene promoter [71]. This promoter region polymorphism is reported to influence the secretion of leptin which is associated with obesity. The authors found that homozygosity for this polymorphism was significantly associated with antipsychotic-induced weight gain. The same polymorphism ( -2548 G/A polymorphism) was investigated by Templeman et al. (2005) in a 9-month study of neuroleptic-naïve patients with schizophrenia from Spain $(n=73)$. The authors found that the polymorphism was associated with weight gain over the 9-month period. The same population has been scrutinized for a 5-HT2C receptor association. Data from the combined leptin and 5-HT2C -759 C/T genotype effect reported by Templeman et al. (2005) indicates that this genetic variability can account for over $25 \%$ of the variance in weight gain. The same team also showed that the 5-HT2C polymorphism, like the leptin polymorphism, influences leptin secretion [72]. On the other hand the $-759 \mathrm{~T}$ allele showed a protective effect and resulted in higher plasma leptin prior to treatment. These findings suggest a pharmacogenetic influence of leptin gene polymorphisms in antipsychotics-induced weight gain.

Perez-Iglesias et al. (2010) studied patients $(n=205)$ who received either haloperidol, olanzapine, risperidone, ziprasidone, aripiprazole, or quetiapine treatment (all antipsychotic treatments were adjusted to the lowest effective dosage), and who were genotyped for rs7799039 LEP and rs1137101 LEPR, but no significant association with BMI or with antipsychotic-induced weight gain was found [73]. As well, the LEPR gene has been investigated by Moons et al. (2010) who have done an association study to examine possible association between LEPR polymorphism rs8179183 and several body parameters in 261 schizophrenia or schizoaffective patients treated typical or atypical antipsychotics with no significant results [74]. Fernandez et al. (2010) conducted a study in clozapine-treated patients who entered a trial to assess the effect of metformin, an antidiabetic medication [75]. Clinical and preclinical findings suggest that metformin affects leptin synthesis and serum levels and enhances leptin and insulin sensitivity. In this study, they first evaluated the frequency of the metabolic syndrome and obesity, anthropometric and biochemical variables before and after randomization, and subsequently compared differences in BW among genotypes (LEP - 2548 G/A and Q223R LEPR). No association was observed between the leptin system polymorphisms and the anthropometric variables during treatment with metformin or placebo. The QQ LEPR genotype has displayed significantly lower triglyceride levels at baseline and showed some of the expected response to metformin. In constrast, the GG LEP genotype has showed a significant increase in glucose after treatment with metformin [75]. Gregoor et al. (2009) performed a cross-sectional analysis to determine whether the LEPR Q223R polymorphism and the LEP promoter $-2548 \mathrm{G} / \mathrm{A}$ polymorphism are associated with obesity and atypical AP treatment [76]. No significant association was found between LEP promoter - $2548 \mathrm{G} / \mathrm{A}$ polymorphism and obesity, while in females, but not in males, the LEPR 223QR and LEPR 223RR genotypes were associated with lower risk of obesity. Srivastava et al. (2008) found that the rs4731426 SNP, a variant in the leptin gene, was moderately associated with median weight gain and significantly associated with extreme weight gain in North India subjects in olanzapine treatment [77]. Leptin has been investigated also by Ellingrod et al. (2007) in a pharmacogenetic association reanalysis of a longitudinal open label fixed-dose trial of olanzapine response and adverse effects [78]. The enrolled subjects were genotyped for the -2548 G/A polymorphism of the leptin gene and the Q223R polymorphism of the leptin gene receptor. Genotypes were not individually associated with olanzapine-induced weight 
gain. Changes in weight from baseline increased significantly in patients carrying at least one $\mathrm{G}$ allele at both candidate loci and high olanzapine plasma levels.

\section{Conclusions}

A majority of research has focused on the effects of clozapine and olanzapine on SLL. The positive modulation of this parameter by the studied atypical antipsychotics has been observed as early as a few hours after the beginning of the treatment, peaking between 6 and 10 weeks after, and remaining elevated for a period of up to several months. With respect to atypical AP treatment, a number of studies found elevated leptin levels following atypical AP medications, in some cases independent of BMI increase.

It is relevant to note that while weight gain with olanzapine and clozapine therapy predominantly occurs over the first 6 months of treatment plateauing after 6 months to 1 year of treatment, leptin changes do not parallel with weight changes during extended AP treatment as pointed out by Bromel et al. [50]. This pattern was replicated by Monteleone et al. (2002) [54], and Theisen et al. (2005) [52] in later studies. In contrast to olanzapine and clozapine, fluctuations in SLL have not been seen in risperidone treatment, which is consistent with the conventional neuroleptic treatment causing less fluctuation in BW.

Weight gain as a result of AP treatment is associated with significant physical and psychological morbidity, and patients undergoing AP treatment have significant and valid concerns about weight gain and weight management. Substantial progress has recently been made in understanding weight gain, energy expenditure rate, and changes in appetite associated with AP treatment, including the identification of markers of obesity risk caused by fluctuation in energy homeostasis, metabolic variation, and energy intake and expenditure during antipsychotic treatment. Among these markers, leptin could play an important role and is associated with weight gain in atypical antipsychotic treatment as seen in the present review.

Although it is true that these changes can be explained by adiposity, and produced and released by adipocytes in response to increased fat deposition to regulate body weight, there is intriguing evidence to support the hypothesis that antipsychotics could induce or exacerbate a leptin-resistance status. Resistance to leptin could generate metabolic conditions resulting in weight gain. Further research is still needed to clarify the relationship between leptin and antipsychotics. The elucidation of these potential mechanisms could be important for quantification of patient risk during treatment with antipsychotics and can spur development of novel forms of treatment.

\section{References}

[1] C. Rummel-Kluge, K. Komossa, S. Schwarz et al., "Headto-head comparisons of metabolic side effects of second generation antipsychotics in the treatment of schizophrenia: a systematic review and meta-analysis," Schizophrenia Research, vol. 123, no. 2-3, pp. 225-233, 2010.
[2] K. T. Mueser and S. R. McGurk, "Schizophrenia," The Lancet, vol. 363, no. 9426, pp. 2063-2072, 2004.

[3] P. Seeman, "Antipsychotic drugs, dopamine receptors, and schizophrenia," Clinical Neuroscience Research, vol. 1, no. 1-2, pp. 53-60, 2001.

[4] D. W. Haupt, "Differential metabolic effects of antipsychotic treatments," European Neuropsychopharmacology, vol. 16, supplement 3, pp. S149-S155, 2006.

[5] G. P. Reynolds and S. L. Kirk, "Metabolic side effects of antipsychotic drug treatment-pharmacological mechanisms," Pharmacology and Therapeutics, vol. 125, no. 1, pp. 169-179, 2010.

[6] M. Han, X. F. Huang, T. M. du Bois, and C. Deng, "The effects of antipsychotic drugs administration on 5-HT1A receptor expression in the limbic system of the rat brain," Neuroscience, vol. 164, no. 4, pp. 1754-1763, 2009.

[7] R. Coccurello and A. Moles, "Potential mechanisms of atypical antipsychotic-induced metabolic derangement: clues for understanding obesity and novel drug design," Pharmacology and Therapeutics, vol. 127, no. 3, pp. 210-251, 2010.

[8] C. Deng, K. Weston-Green, and X. F. Huang, "The role of histaminergic $\mathrm{H} 1$ and $\mathrm{H} 3$ receptors in food intake: a mechanism for atypical antipsychotic-induced weight gain?” Progress in Neuro-Psychopharmacology and Biological Psychiatry, vol. 34, no. 1, pp. 1-4, 2010.

[9] H. Blasco-Fontecilla, E. Baca-Garcia, and J. de Leon, "Do atypical antipsychotic drugs reduce the risk of ischemic heart disease and mortality? Possible role of 5-HT2A receptor blockade," Schizophrenia Research, vol. 119, no. 1-3, pp. 160$163,2010$.

[10] S. Choi, B. DiSilvio, J. Unangst, and J. D. Fernstrom, "Effect of chronic infusion of olanzapine and clozapine on food intake and body weight gain in male and female rats," Life Sciences, vol. 81, no. 12, pp. 1024-1030, 2007.

[11] A. Esen-Danaci, A. Sarandol, F. Taneli, F. Yurtsever, and N. Özlen, "Effects of second generation antipsychotics on leptin and ghrelin," Progress in Neuro-Psychopharmacology and Biological Psychiatry, vol. 32, no. 6, pp. 1434-1438, 2008.

[12] J. Harvey and M. L. J. Ashford, "Leptin in the CNS: much more than a satiety signal," Neuropharmacology, vol. 44, no. 7, pp. 845-854, 2003.

[13] F. C. J. Starrenburg and J. P. A. M. Bogers, "How can antipsychotics cause diabetes mellitus? Insights based on receptorbinding profiles, humoral factors and transporter proteins," European Psychiatry, vol. 24, no. 3, pp. 164-170, 2009.

[14] F. Zhang, Y. Chen, M. Heiman et al., "Leptin: structure, function and biology," in Vitamins \& Hormones, L. Gerald, Ed., pp. 345-372, Academic Press, 2005.

[15] G. Sweeney, "Leptin signalling," Cellular Signalling, vol. 14, no. 8, pp. 655-663, 2002.

[16] H. Funahashi, T. Yada, R. Suzuki et al., "Distribution, function, and properties of leptin receptors in the brain," in International Review of Cytology, W. J. Kwang, Ed., pp. 1-27, Academic Press, 2003.

[17] D. O. Yarnell, D. S. Knight, K. Hamilton, O. Tulp, and P. Tso, "Localization of leptin receptor immunoreactivity in the lean and obese Zucker rat brain," Brain Research, vol. 785, no. 1, pp. 80-90, 1998.

[18] C. Buchanan, V. Mahesh, P. Zamorano, and D. Brann, "Central nervous system effects of leptin," Trends in Endocrinology and Metabolism, vol. 9, no. 4, pp. 146-150, 1998.

[19] A. Buison, F. Ordiz, and K. L. C. Jen, "Long-term effects of exogenous leptin on body weight and fat in post-obese female 
rats," Physiology and Behavior, vol. 74, no. 3, pp. 321-328, 2001.

[20] G. A. Wittert, H. Turnbull, and P. Hope, "Exogenously administered leptin leads to weight loss and increased physical activity in the marsupial Sminthopsis crassicaudata," Physiology and Behavior, vol. 85, no. 5, pp. 613-620, 2005.

[21] J. López-Soriano, N. Carbó, F. J. López-Soriano, and J. M. Argilés, "Short-term effects of leptin on lipid metabolism in the rat," FEBS Letters, vol. 431, no. 3, pp. 371-374, 1998.

[22] S. P. Kalra, "Central leptin insufficiency syndrome: an interactive etiology for obesity, metabolic and neural diseases and for designing new therapeutic interventions," Peptides, vol. 29, no. 1, pp. 127-138, 2008.

[23] T. L. Breen, I. M. Conwell, and S. L. Wardlaw, "Effects of fasting, leptin, and insulin on AGRP and POMC peptide release in the hypothalamus," Brain Research, vol. 1032, no. 12, pp. 141-148, 2005.

[24] L. K. Malendowicz, M. Rucinski, A. S. Belloni et al., "Leptin and the regulation of the hypothalamic-pituitary-adrenal axis," in International Review of Cytology, W. J. Kwang, Ed., pp. 63-102, Academic Press, 2007.

[25] J. E. Johansen, C. Broberger, C. Lavebratt et al., "Hypothalamic CART and serum leptin levels are reduced in the anorectic (anx/anx) mouse," Molecular Brain Research, vol. 84, no. 1-2, pp. 97-105, 2000.

[26] G. Orlando, L. Brunetti, C. Di Nisio et al., "Effects of cocaineand amphetamine-regulated transcript peptide, leptin and orexins on hypothalamic serotonin release," European Journal of Pharmacology, vol. 430, no. 2-3, pp. 269-272, 2001.

[27] T. Shiraishi, Y. Oomura, K. Sasaki, and M. J. Wayner, "Effects of leptin and orexin-A on food intake and feeding related hypothalamic neurons," Physiology and Behavior, vol. 71, no. 3-4, pp. 251-261, 2000.

[28] T. Shiraishi, K. Sasaki, A. Niijima, and Y. Oomura, "Leptin effects on feeding-related hypothalamic and peripheral neuronal activities in normal and obese rats," Nutrition, vol. 15, no. 7-8, pp. 576-579, 1999.

[29] N. S. Narayanan, D. J. Guarnieri, and R. J. DiLeone, "Metabolic hormones, dopamine circuits, and feeding," Frontiers in Neuroendocrinology, vol. 31, no. 1, pp. 104-112, 2010.

[30] M. S. Szczypka, K. Kwok, M. D. Brot et al., "Dopamine production in the caudate putamen restores feeding in dopaminedeficient mice," Neuron, vol. 30, no. 3, pp. 819-828, 2001.

[31] R. D. Palmiter, "Is dopamine a physiologically relevant mediator of feeding behavior?" Trends in Neurosciences, vol. 30, no. 8, pp. 375-381, 2007.

[32] J. Hao, S. Cabeza de Vaca, Y. Pan, and K. D. Carr, "Effects of central leptin infusion on the reward-potentiating effect of damphetamine," Brain Research, vol. 1087, no. 1, pp. 123-133, 2006.

[33] C. M. Cannon, L. Abdallah, L. H. Tecott, M. J. During, and R. D. Palmiter, "Dysregulation of striatal dopamine signaling by amphetamine inhibits feeding by hungry mice," Neuron, vol. 44, no. 3, pp. 509-520, 2004.

[34] A. Hamdi, J. Porter, and P. Chandan, "Decreased striatal D2 dopamine receptors in obese Zucker rats: changes during aging," Brain Research, vol. 589, no. 2, pp. 338-340, 1992.

[35] N. D. Volkow, G.-J. Wang, F. Telang et al., "Low dopamine striatal D2 receptors are associated with prefrontal metabolism in obese subjects: possible contributing factors," NeuroImage, vol. 42, no. 4, pp. 1537-1543, 2008.

[36] K. D. Carr, "Chronic food restriction: enhancing effects on drug reward and striatal cell signaling," Physiology and Behavior, vol. 91, no. 5, pp. 459-472, 2007.
[37] L. Kostál, P. Výboh, C. J. Savory, M. Juráni, L. Kubíková, and P. Blažíček, "Influence of food restriction on dopamine receptor densities, catecholamine concentrations and dopamine turnover in chicken brain," Neuroscience, vol. 94, no. 1, pp. 323-328, 1999.

[38] N. D. Barnard, E. P. Noble, T. Ritchie et al., "D2 dopamine receptor Taq1A polymorphism, body weight, and dietary intake in type 2 diabetes," Nutrition, vol. 25, no. 1, pp. 58-65, 2009.

[39] Y.-J. Fang, G. N. Thomas, Z.-L. Xu, J. Q. Fang, J. A. J. H. Critchley, and B. Tomlinson, "An affected pedigree member analysis of linkage between the dopamine D2 receptor gene TaqI polymorphism and obesity and hypertension," International Journal of Cardiology, vol. 102, no. 1, pp. 111-116, 2005.

[40] Z. Jovanovic and G. S. H. Yeo, "Central leptin signalling: beyond the arcuate nucleus," Autonomic Neuroscience: Basic and Clinical, vol. 156, no. 1-2, pp. 8-14, 2010.

[41] D. M. Opland, G. M. Leinninger, and J. M. G. Myers, "Modulation of the mesolimbic dopamine system by leptin," Brain Research C, vol. 1350, pp. 65-70, 2010.

[42] L. Brunetti, B. Michelotto, G. Orlando, and M. Vacca, "Leptin inhibits norepinephrine and dopamine release from rat hypothalamic neuronal endings," European Journal of Pharmacology, vol. 372, no. 3, pp. 237-240, 1999.

[43] U. Krügel, T. Schraft, H. Kittner, W. Kiess, and P. Illes, "Basal and feeding-evoked dopamine release in the rat nucleus accumbens is depressed by leptin," European Journal of Pharmacology, vol. 482, no. 1-3, pp. 185-187, 2003.

[44] T. Morimoto, Y. Yamamoto, J. I. Mobarakeh et al., "Involvement of the histaminergic system in leptin-induced suppression of food intake," Physiology and Behavior, vol. 67, no. 5, pp. 679-683, 1999.

[45] T. Ishiguro, M. Iwase, M. Kanamaru, M. Izumizaki, Y. Ohshima, and I. Homma, "Impaired ventilation and metabolism response to hypoxia in histamine $\mathrm{H} 1$ receptor-knockout mice," Respiratory Physiology and Neurobiology, vol. 154, no. 3, pp. 331-341, 2006.

[46] S. Ogawa, K. Yanai, T. Watanabe et al., "Histamine responses of large neostriatal interneurons in histamine $\mathrm{H} 1$ and $\mathrm{H} 2$ receptor knock-out mice," Brain Research Bulletin, vol. 78, no. 4-5, pp. 189-194, 2009.

[47] Y. Zhang and P. J. Scarpace, "The role of leptin in leptin resistance and obesity," Physiology and Behavior, vol. 88, no. 3, pp. 249-256, 2006.

[48] S. Peralta, J. M. Carrascosa, N. Gallardo, M. Ros, and C. Arribas, "Ageing increases SOCS-3 expression in rat hypothalamus: effects of food restriction," Biochemical and Biophysical Research Communications, vol. 296, no. 2, pp. 425-428, 2002.

[49] C. Bjørbæk, J. K. Elmquist, J. D. Frantz, S. E. Shoelson, and J. S. Flier, "Identification of SOCS-3 as a potential mediator of central leptin resistance," Molecular Cell, vol. 1, no. 4, pp. 619-625, 1998.

[50] T. Bromel, W. F. Blum, A. Ziegler et al., "Serum leptin levels increase rapidly after initiation of clozapine therapy," Molecular Psychiatry, vol. 3, no. 1, pp. 76-80, 1998.

[51] B. B. Kivircik, K. Alptekin, S. Çalişkan et al., "Effect of clozapine on serum leptin, insulin levels, and body weight and composition in patients with schizophrenia," Progress in Neuro-Psychopharmacology and Biological Psychiatry, vol. 27, no. 5, pp. 795-799, 2003.

[52] F. M. Theisen, S. Gebhardt, T. Bromel et al., "A prospective study of serum ghrelin levels in patients treated with clozapine," Journal of Neural Transmission, vol. 112, no. 10, pp. 14111416, 2005. 
[53] S. Hagg, S. Soderberg, B. Ahren, T. Olsson, and T. Mjorndal, "Leptin concentrations are increased in subjects treated with clozapine or conventional antipsychotics," Journal of Clinical Psychiatry, vol. 62, no. 11, pp. 843-848, 2001.

[54] P. Monteleone, M. Fabrazzo, A. Tortorella, S. La Pia, and M. Maj, "Pronounced, early increase in circulating leptin predicts lower weight gain during clozapine treatment," Journal of Clinical Psychopharmacology, vol. 22, no. 4, pp. 424-426, 2002.

[55] K. A. Graham, D. O. Perkins, J. B. Harp et al., "Investigation of olanzapine-associated weight gain in first episode subjects," Schizophrenia Research, vol. 60, no. 1, supplement 1, pp. 355356, 2003.

[56] M. Murashita, I. Kusumi, T. Inoue et al., "Olanzapine increases plasma ghrelin level in patients with schizophrenia," Psychoneuroendocrinology, vol. 30, no. 1, pp. 106-110, 2005.

[57] H. Hosojima, T. Togo, T. Odawara et al., "Early effects of olanzapine on serum levels of ghrelin, adiponectin and leptin in patients with schizophrenia," Journal of Psychopharmacology, vol. 20, no. 1, pp. 75-79, 2006.

[58] C.-J. Wang, Z.-J. Zhang, J. Sun et al., "Serum free fatty acids and glucose metabolism, insulin resistance in schizophrenia with chronic antipsychotics," Biological Psychiatry, vol. 60, no. 12, pp. 1309-1313, 2006.

[59] R. Peña, D. Marquina, A. Serrano et al., "Frequency of abnormal correlation between leptin and the body mass index during first and second generation antipsychotic drug treatment," Schizophrenia Research, vol. 106, no. 2-3, pp. 315-319, 2008.

[60] V. Popovic, M. Doknic, N. Maric et al., "Changes in neuroendocrine and metabolic hormones induced by atypical antipsychotics in normal-weight patients with schizophrenia," Neuroendocrinology, vol. 85, no. 4, pp. 249-256, 2007.

[61] U. Eder, B. Mangweth, C. Ebenbichler et al., "Association of olanzapine-induced weight gain with an increase in body fat," American Journal of Psychiatry, vol. 158, no. 10, pp. 1719-1722, 2001.

[62] M. Atmaca, E. Tezcan, and B. Ustundag, "Plasma nitric oxide and leptin values in patients with olanzapine-induced weight gain," Journal of Psychiatric Research, vol. 41, no. 1-2, pp. 7479, 2007.

[63] M. Atmaca, M. Kuloglu, E. Tezcan, O. Gecici, and B. Ustundag, "Weight gain, serum leptin and triglyceride levels in patients with schizophrenia on antipsychotic treatment with quetiapine, olanzapine and haloperidol," Schizophrenia Research, vol. 60, no. 1, pp. 99-100, 2003.

[64] T. Kraus, M. Haack, A. Schuld et al., "Body weight and leptin plasma levels during treatment with antipsychotic drugs," American Journal of Psychiatry, vol. 156, no. 2, pp. 312-314, 1999.

[65] Z. Zhang, Z. J. Yao, W. Liu et al., "Assessment of fat distribution by MRI, and changes in leptin and insulin associated with drug treatment of first episode schizophrenic patients," Schizophrenia Research, vol. 60, no. 1, supplement 1, pp. 372 372, 2003.

[66] A. Herran, M. T. Garcia-Unzueta, J. A. Amado, M. T. De La Maza, C. Alvarez, and J. L. Vázquez-Barquero, "Effects of longterm treatment with antipsychotics on serum leptin levels," British Journal of Psychiatry, vol. 179, pp. 59-62, 2001.

[67] D. W. Haupt, J. A. Schweiger, A. K. Melson et al., "Plasma leptin in treated patients with schizophrenia," Schizophrenia Research, vol. 60, no. 1, supplement 1, pp. 356-356, 2003.

[68] H. Hauner, "The new concept of adipose tissue function," Physiology and Behavior, vol. 83, no. 4, pp. 653-658, 2004.

[69] G. D. Cooper, J. A. Harrold, J. C. G. Halford, and A. J. Goudie, "Chronic clozapine treatment in female rats does not induce weight gain or metabolic abnormalities but enhances adiposity: implications for animal models of antipsychoticinduced weight gain," Progress in Neuro-Psychopharmacology and Biological Psychiatry, vol. 32, no. 2, pp. 428-436, 2008.

[70] S. Sondhi, J. M. Castellano, V. Z. Chong et al., "cDNA array reveals increased expression of glucose-dependent insulinotropic polypeptide following chronic clozapine treatment: role in atypical antipsychotic drug-induced adverse metabolic effects," Pharmacogenomics Journal, vol. 6, no. 2, pp. 131-140, 2006.

[71] D. Yang, H. Chen, X. Wang et al., "Association of polymorphisms of lptin gene with body weight and body sizes indexes in Chinese indigenous cattle," Journal of Genetics and Genomics, vol. 34, no. 5, pp. 400-405, 2007.

[72] L. A. Templeman, G. P. Reynolds, B. Arranz, and L. San, "Polymorphisms of the 5-HT2C receptor and leptin genes are associated with antipsychotic drug-induced weight gain in Caucasian subjects with a first-episode psychosis," Pharmacogenetics and Genomics, vol. 15, no. 4, pp. 195-200, 2005.

[73] R. Perez-Iglesias, I. Mata, J. A. Amado et al., "Effect of FTO, SH2B1, LEP, and LEPR polymorphisms on weight gain associated with antipsychotic treatment," Journal of Clinical Psychopharmacology, vol. 30, no. 6, pp. 661-666, 2010.

[74] T. Moons, S. Claes, G. J. Martens et al., "Clock genes and body composition in patients with schizophrenia under treatment with antipsychotic drugs," Schizophrenia Research, vol. 125, no. 2-3, pp. 187-193, 2010.

[75] E. Fernandez, E. Carrizo, V. Fernandez et al., "Polymorphisms of the LEP- and LEPR genes, metabolic profile after prolonged clozapine administration and response to the antidiabetic metformin," Schizophrenia Research, vol. 121, no. 1-3, pp. 213-217, 2010.

[76] J. G. Gregoor, J. van der Weide, H. Mulder et al., "Polymorphisms of the LEP- and LEPR gene and obesity in patients using antipsychotic medication," Journal of Clinical Psychopharmacology, vol. 29, no. 1, pp. 21-25, 2009.

[77] V. Srivastava, S. N. Deshpande, V. L. Nimgaonkar, B. Lerer, and B. K. Thelma, "Genetic correlates of olanzapine-induced weight gain in schizophrenia subjects from north India: role of metabolic pathway genes," Pharmacogenomics, vol. 9, no. 8, pp. 1055-1068, 2008.

[78] V. L. Ellingrod, J. R. Bishop, J. Moline, Y. C. Lin, and D. D. Miller, "Leptin and leptin receptor gene polymorphisms and increases in body mass index (BMI) from olanzapine treatment in persons with schizophrenia," Psychopharmacology Bulletin, vol. 40, no. 1, pp. 57-62, 2007. 


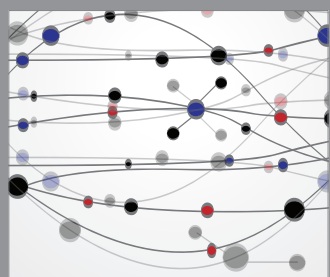

The Scientific World Journal
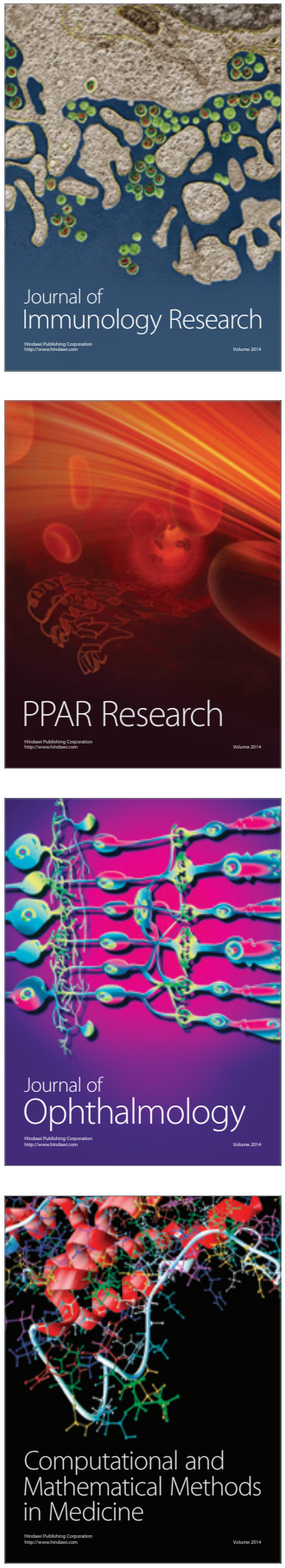

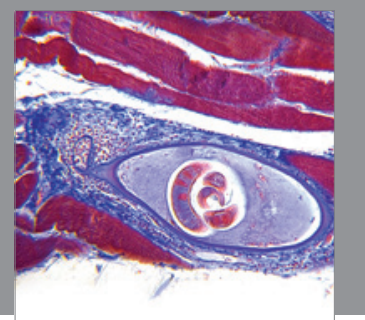

Gastroenterology

Research and Practice
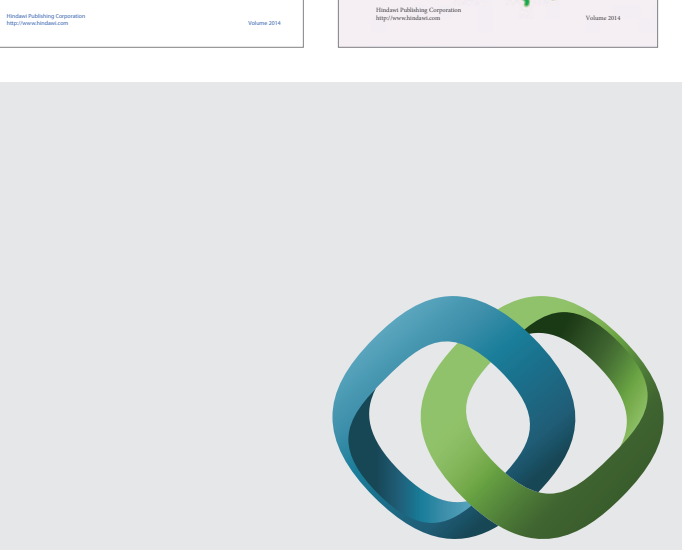

\section{Hindawi}

Submit your manuscripts at

http://www.hindawi.com
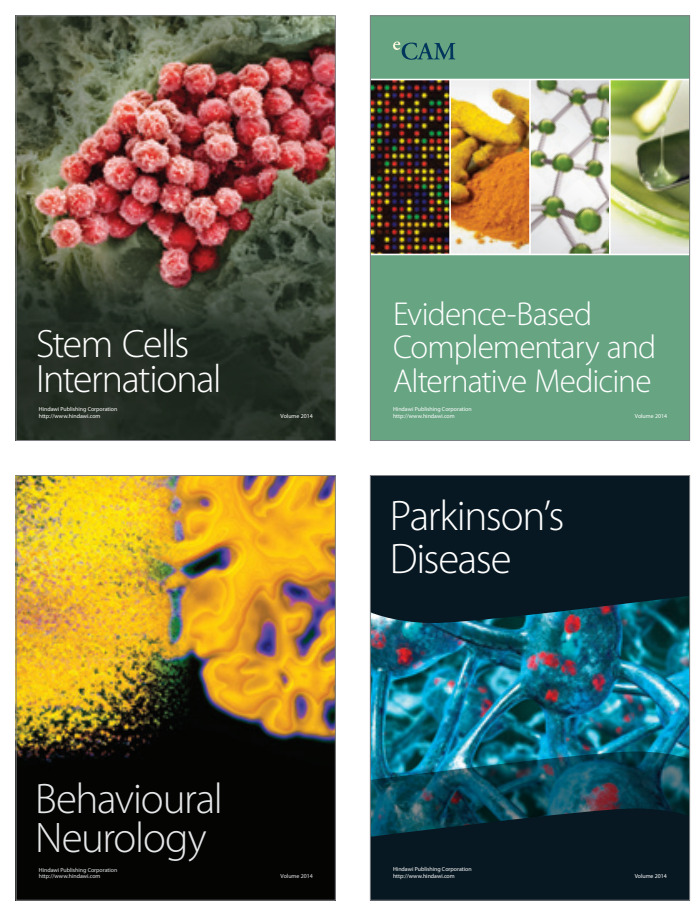

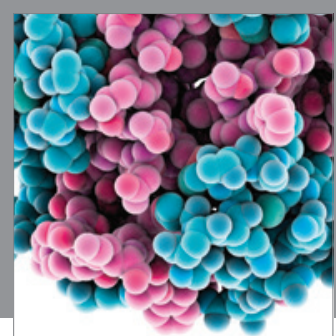

Journal of
Diabetes Research

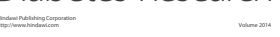

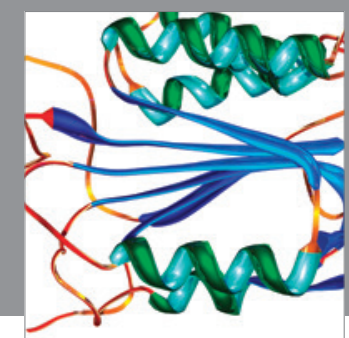

Disease Markers
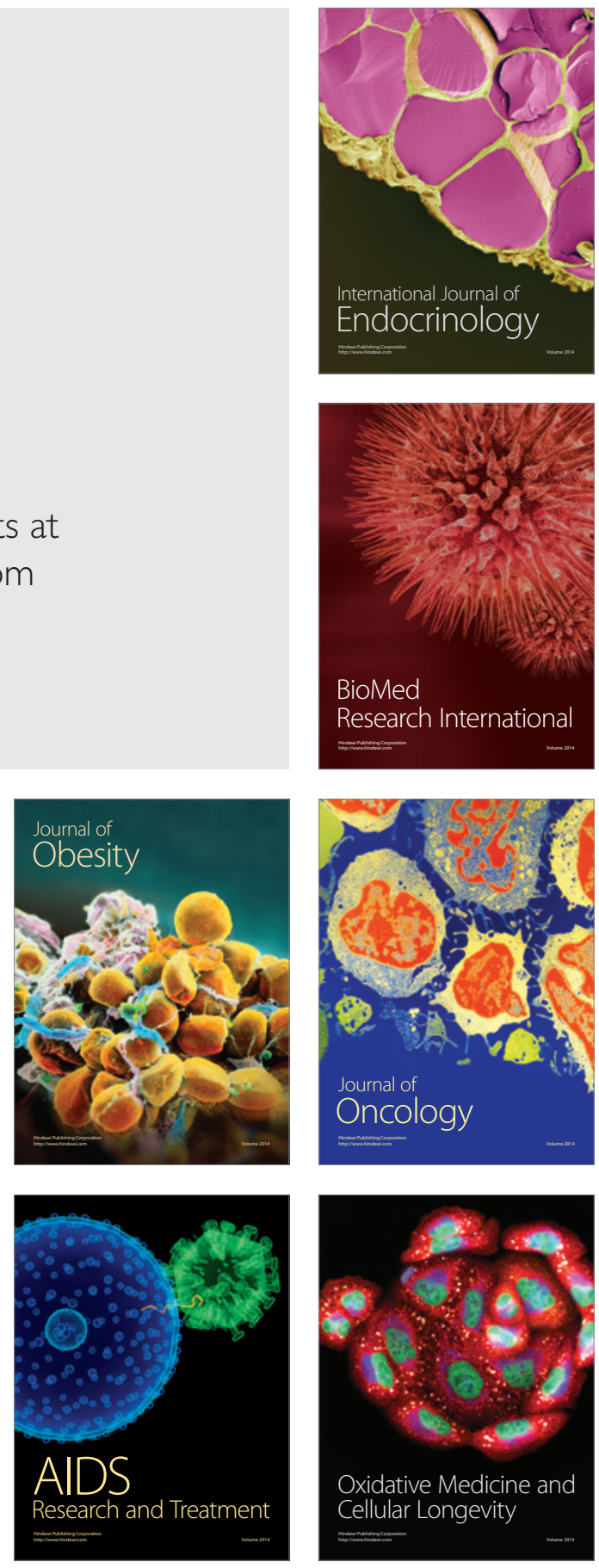